\title{
Waste Water Purification from Metal lons by Ultra-Dispersed Natural Sorbents
}

\author{
Sezim Yerbolov', Gulzhan Daumova ${ }^{1 *}$ \\ 1 D. Serikbayev East Kazakhstan Technical University, 19, Serikbayev str., Ust-Kamenogorsk, 070000, Kazakhstan \\ * Corresponding author's e-mail: gulzhan.daumova@mail.ru
}

\begin{abstract}
This work is devoted to mine wastewater purification from metal ions, such as copper, zinc, lead, cadmium, iron, and manganese. The rationale was provided for the possibility to purify the wastewater from metal ions with nonactivated and ultra-dispersed natural sorbents. The adsorption capacity of bentonite clay from Tagan deposit and shungite from Koksui deposit of the Republic of Kazakhstan was studied on the basis of its fraction composition. It was found that the most effective method of sorbents modification was mechanical activation. The comparative studies of metal ions adsorption efficiency were carried out with mechanically activated and ultra-dispersed bentonite clay and shungite. The experiment enabled to find out that ultra-dispersed bentonite clay is prospective for use in order to deeply purify multicomponent mine wastewater. The highest degree of metal ions extraction was achieved due to 30-minutes contact of wastewater.
\end{abstract}

Keywords: wastewater, metal ions, bentonite clay, shungites, mechanical activation, ultra-dispersed sorbent.

\section{INTRODUCTION}

Nowadays, wastewater purification from heavy metal ions is a relevant global issue. The environment pollution with mine wastewater is a similar scale issue that also has a global effect. A considerable amount of wastewater is discharged by mining and metallurgical enterprises and it causes severe water bodies pollution. It makes fishery management and potable water intake challenging. Although there are waste treatment facilities at most enterprises that prevent discharge of completely contaminated wastewater into water basins, the current problem is not entirely resolved.

The issue of wastewater purification is also relevant for East Kazakhstan. Historical industrial pollution caused by mining and metallurgical industries of East Kazakhstan, significantly affects the water quality. The source of rivers contamination is under-treated wastewater from mining enterprises of East Kazakhstan. They include Irtyshsky mine, mining enterprise, its wastewater contains a large amount of heavy non-ferrous metals and other contaminants. The level of underground and surface water pollution within the contamination boundaries is exceeded in terms of manganese and cadmium content. Enhancement of environmental standards and increasingly stringent requirements for the surface water quality dictate the search for more efficient methods of pollutants removal from waste water. As a result, efficient technological and economic methods for wastewater purification from metal ions are being developed.

The amount of different pollutants, including heavy metal ions [Masindi et al., 2018. Rajasulochana et al., 2016], infiltrating the wastewater system, increases rapidly due to industry development. Therefore, wastewater treatment is becoming more and more relevant, which is reflected in a range of studies devoted to this theme. There are a great number of different methods of wastewater purification from heavy metal ions [Iakovleva and Sillanpää, 2020].

In order to purify this wastewater, usually reactant purification is used when heavy metal ions are transferred to insoluble hydroxides with 
alkaline agents [Droste and Gehr, 2019]. However, this technology has some disadvantages: high consumption of expensive reagents, precipitation of heavy metals hydroxides is not complete due to the change of their concentrates and $\mathrm{pH}$ flows, heavy metal ions breakthrough treatment facilities into the composition of purified wastewater. Besides, the classical method of wastewater treatment does not provide its deep purification from metal ions, as their remaining content exceeds the MPC norms several times.

In recent years, the scale of conducted studies related to heavy non-ferrous metals removal from mine wastewater has increased. Heavy non-ferrous metals are removed by using the biochemical method involving different bacterial cultures [Rambabu et al., 2020]. Recently, electrochemical methods have become widely used for removing heavy metals from wastewater. [Tezcan et al., 2017], [Al-Qodah et al., 2017] used electric coagulation, [Brahmi et al., 2018] suggested the electric flocculation method, whereas [Yenial et al., 2017] applied electric flotation. The main disadvantage of these methods is high consumption of electric power.

Efficiency and producibility of metal compounds recovery are achieved by membrane separation methods, i.e. reverse osmosis and ultrafiltration [Ali et al., 2021], as well as the use of acid-resistant membranes [Zhu et al., 2020]. The methods mentioned above are not yet widely used in mines due to considerable electric power consumption, operation complexity, no selectivity, deficiency and high price of membranes. It should be noted that the environmental impact of using membrane technologies for purification of wastewater including, membrane pollution, must be taken into account [Zheng et al., 2015].

Ionites can also be used for ion-exchange purification of wastewater from metal ions [Koliehova et al., 2019]. The disadvantages of this method are as follows: high consumption of reagents for ionites regeneration and resins processing, formation of secondary wastes, high price of resins, and complexity due to multi-stage processing with ionites. Thus, nowadays there is a wide range of methods that enable to purify wastewater as well as obtain circulating water and product that is suitable for further use. However, none of these methods can be considered universal, as they do not comply with standards in all cases.

Among practical technologies, sorption is one of the most efficient and economically advantageous methods for removing heavy metals from a water medium [Shahmirzadi et al., 2018]. This water purification method provides high purification level of heavily polluted wastewater. The most widely spread sorption materials for heavy metals are synthetic sorbents [Ermolenko, 2020], synthetic zeolite, chitosan [Płaza et al., 2017], carbon materials [Xue et al., 2018]. It should be noted that synthetic sorbents and carbon are characterized by a range of disadvantages that constrain their wide use. The disadvantages include high cost and limited amounts.

The use of natural and inexpensive sorbents is of great interest due to simple process and potential efficiency. The sorbents of natural origin (bentonite clay, shungites, and other clay materials) have rather high sorption capacity, while their cost is relatively low. They are available especially in the cases when their deposits are close to industrial enterprises where these sorbents can be used. Due to high adsorption properties and highwater retention capacity, bentonite clay and shungites are effectively used for water purification from organic and non-organic impurities. The useful properties of bentonite clay and shungites are defined by specific structural features and unique ion-exchange capacity. Sorbents of natural origin are characterized by high sorption capacity and good ion-exchange properties [Aziz et al., 2019].

Layered aluminosilicate-based natural sorbents (shungites, bentonite clay) are rather cheap and widely used. However, their sorption properties considerably depend on many external factors. Consequently, there is a need to modify the original raw material before its practical use. It is known that the synthesis of bentonite clay with high sorption capacity efficiently absorbs different metal ions from wastewater [Mamyachenkov et al., 2017]. When bentonite clays and shungites of East Kazakhstan deposits were studied, the following advantages were defined: high sorption properties; low cost (in comparison with the reagents used in water purification technology); temperature and climatic conditions resistance during haulage, storage and operation. The technological parameters of the wastewater sorption purification process require a search for a sorbent with low production cost. It can be achieved by activation and modification of clay minerals in order to increase their sorption capacity [Uddin, 2017], and also by using modified bentonite compositions [Pandey, 2017]. 
Most natural sorbents have low sorption capacities under normal conditions. They can be activated by physical methods in the form of additional thermal treatment of sorbents [Zivica and Palou, 2015], or due to chemical treatment [Toor et al., 2015]. Bentonite clays modification can reveal itself in changing the chemical nature of external and internal silicon-oxygen surface of a particle, in displacement of interlayer water, in exchange of alkali (alkaline-earth) metals cations for the other nonorganic cations. Activation enables to enhance the quality of bentonite clays. [Pawar et al., 2016] suggested acid activation of bentonite, [Masindi et al., 2017] suggested synthesis of cryptocrystalline magnesium bentonite clay composite, and [Djab and Makhoukhi, 2018] suggested bentonite modification with the use of salts, steam, meta-, ortho-, bis- imidazole. It is known that the chemical reagents used for activation of modified sorbents cause secondary pollution.

The provided review of the existing methods of sorbents activation proves that they require the use of expensive chemicals and additional binders for production of sorbents. This affects the cost of finished products and purification. Development of effective and cheap sorbents for wastewater purification is still an open question though it is very important. Within these frameworks it is also sufficient to develop a technology for natural sorbents modification, to enhance their sorption properties. Kumrič et al. [2013] found out that the sorption characteristics of natural sorbents can be improved as a result of mechanical activation. It is provided by partial decomposition of crystalline lattice and development of sorbent specific surface. It was studied earlier that bentonite clay and basalt fiber composition in mechano-activated state is effective for extraction of chromium ions from electroplating industry wastewater [Daumova et al., 2018].

Thus, the priority direction in studies is the synthesis of new highly-efficient sorbents based on bentonite clay of Tagan deposit and shungites of the Republic of Kazakhstan that meet the specified requirements. Carrying out studies on wastewater purification from metal ions is a priority objective in solving the problems of global environment conditions. It makes this issue relevant and requires constant studying and identification of new effective and prospective methods that will enable to minimize the anthropogenic impact. Mechanically activated natural ultra-dispersed sorbents of Kazakhstan deposits were used in the given work for purification of mining enterprise wastewater from metal ions on the example of the Irtyshsky mine.

\section{MATERIALS AND METHODS}

Experimental studies on wastewater purification from metal ions were carried out on the actual wastewater of the Irtyshsky mine (East Kazakhstan). Metal ions sorption was studied in static mode with constant stirring. Sorption time varied from 15 to 120 minutes, and sorbent fraction were different. The S:L ratio (sorbent : wastewater) was $1: 100$. The content of metal ions before and after purification was defined by using the absorption method with an inductively coupled (ICP-MSAgilent $5700 \mathrm{cx}$ ) mass spectrometer [Agilent, 2019] produced by the Agilent Technologies company (USA). The rate of extraction $(\alpha, \%)$ was defined based on the obtained experimental data. The rate of extraction shows the share of substance absolute amount recovered by sorbent and provides a comprehensive overview of the process nature. This index is calculated according to the following formula:

$$
\alpha=\frac{C_{o}-C}{C_{o}} \times 100, \%
$$

where: $C_{O}$-initial content of the component in wastewater, $\mathrm{mg} / \mathrm{dm}^{3} ; C$ - residual concentration of the component in wastewater, $\mathrm{mg} / \mathrm{dm}^{3}$.

Mechanical activation of natural sorbents was carried out by drying coarse natural sorbent until its constant weight at temperature $100^{\circ} \mathrm{C}$. Afterwards, the sorbents were ground in a jaw crusher (fraction: $0.5-1.0 ; 1.0-2.5 ; 3.0-5.0 \mathrm{~mm}$ ). Then, the ground sorbent was fed into the grinding chamber of an SVU- vibration mill 2 with grinding bodies. The holding capacity of the grinding chamber is 11 . The charge material grain size is up to $5 \mathrm{~mm}$. The grinding cycle time depends on initial characteristics of ground materials. The grinding time ranged in the interval of 15-20 minutes, depending on the sorbent type.

The obtained ultra-dispersed sorbent is a paste characterized by aggregative stability, i.e. preserves its space structure unchangeable. The moisture of the obtained paste is $60 \%$, its density is $1950 \mathrm{~kg} / \mathrm{m}^{3}$. Mechanical activation enables to reduce the sorbent particles size in average from 60 to $0.250 \mu \mathrm{m}$, the size of considerable part of 
Table 1. Average chemical composition of Koksu shungites

\begin{tabular}{|c|c|}
\hline Basic components & Percentage content, \% \\
\hline Carbon & $4.5-12.0$ \\
\hline $\mathrm{SiO}_{2}$ & $29.0-42.0$ \\
\hline $\mathrm{Al}_{2} \mathrm{O}_{3}$ & $5.0-9.0$ \\
\hline $\mathrm{K}_{2} \mathrm{O}$ & $1.5-3.0$ \\
\hline $\mathrm{CaO}$ & 32.0 \\
\hline $\mathrm{Fe}_{2} \mathrm{O}_{3}$ & 4.52 \\
\hline
\end{tabular}

Table 2. Chemical composition of bentonite clays from the Tagan deposit

\begin{tabular}{|c|c|}
\hline Basic components & Percentage content, \% \\
\hline $\mathrm{SiO}_{2}$ & 55.48 \\
\hline $\mathrm{Al}_{2} \mathrm{O}_{3}$ & 19.38 \\
\hline $\mathrm{K}_{2} \mathrm{O}$ & 0.51 \\
\hline $\mathrm{CaO}$ & 1.98 \\
\hline $\mathrm{TiO}_{2}$ & 0.30 \\
\hline $\mathrm{Fe}_{2} \mathrm{O}_{3}$ & 4.40 \\
\hline $\mathrm{MgO} \mathrm{O}$ & 2.18 \\
\hline $\mathrm{Na}_{2} \mathrm{O}$ & 0.14 \\
\hline $\mathrm{SO}_{3}$ & 0.18 \\
\hline
\end{tabular}

particles was up to $50 \mathrm{~nm}$. After activation, these materials have high surface area and developed surface. Sorbents of different nature were used in the work: shungite and bentonite clay.

Koksu shungites (Almaty region, the Republic of Kazakhstan) were studied for wastewater purification in the conducted scientific research. Average chemical composition of Koksu shungites is provided in Table 1.

In addition, bentonite clays of the Tagan deposit were studied as sorbent. Very valuable Tagan deposits clays were found, in which the content of montmorillonite minerals exceeds $90 \%$. The chemical composition of bentonite clays is characterized by the parameters provided in Table 2 .

\section{RESULTS AND DISCUSSION}

The results of conducted studies on metal ions sorption by natural non-activated shungite of different fractions are shown in Figures 1-3.

The represented studies and graphs referring to them show the direct dependence of the efficiency of wastewater purification degree on sorbent fractions, i.e. the lesser the fraction is, the higher the purification degree. In order to compare the sorption properties of natural materials recommended for improving the water quality, natural non-activated bentonite clay of horizon 14 was studied. It is characterized by high sorption properties. Water was treated with bentonite clay under the similar conditions provided for shungite. The results of the conducted studies on metal ions sorption with natural bentonite clay of different fractions are provided in Figures 4-6.

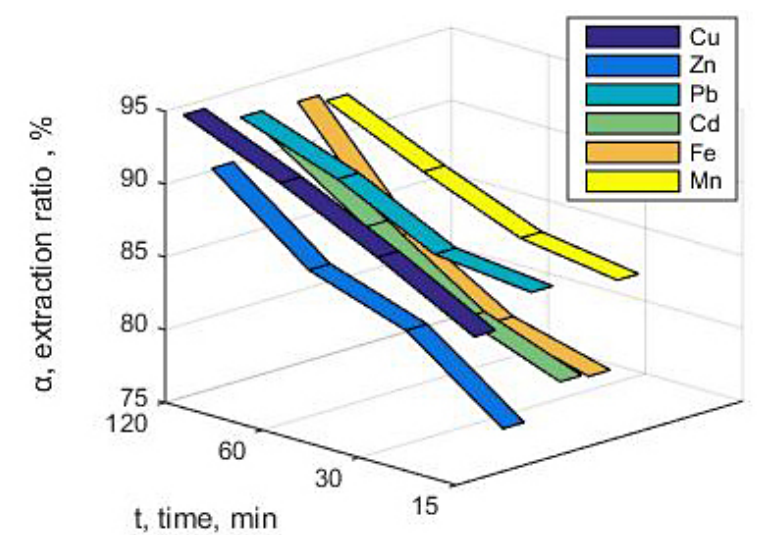

Figure 1. Metal ions extraction by shungite (fractions $0.5-1.0 \mathrm{~mm}$ )

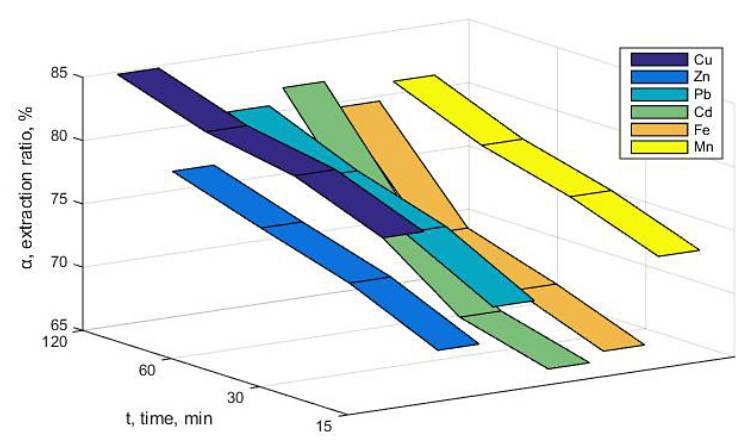

Figure 2. Metal ions extraction by shungite (fractions 1.0 - $2.5 \mathrm{~mm}$ )

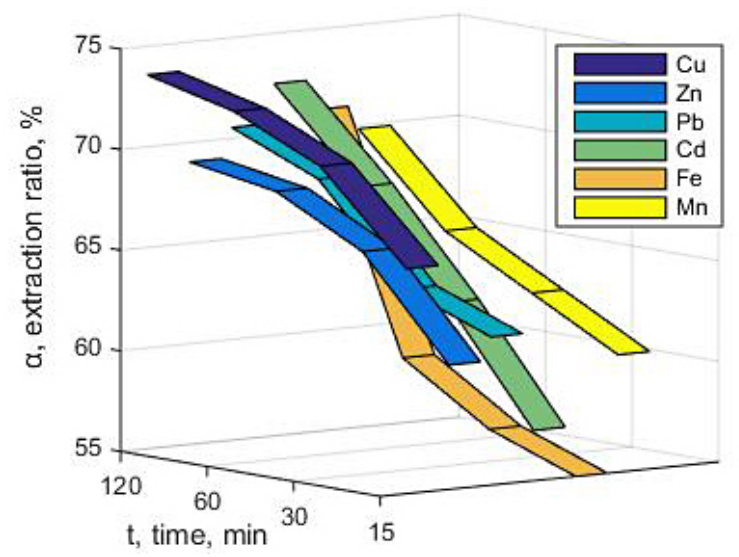

Figure 3. Metal ions extraction by shungite (fractions $3.0-5.0 \mathrm{~mm}$ ) 


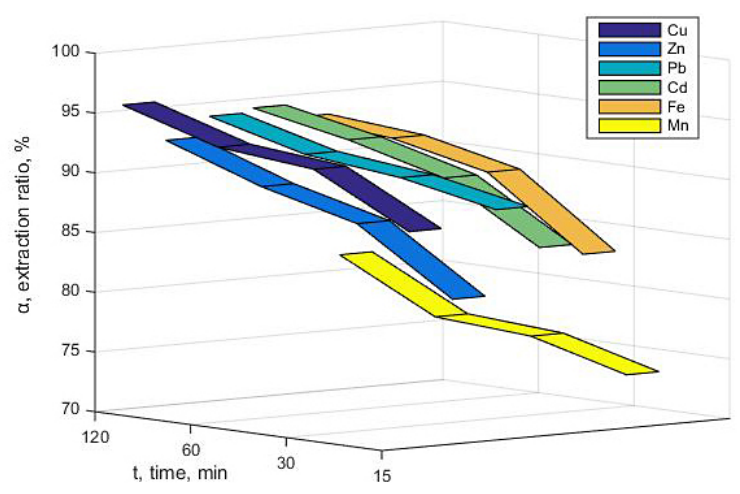

Figure 4. Metal ions extraction by bentonite clay (fractions $0.5-1.0 \mathrm{~mm}$ )

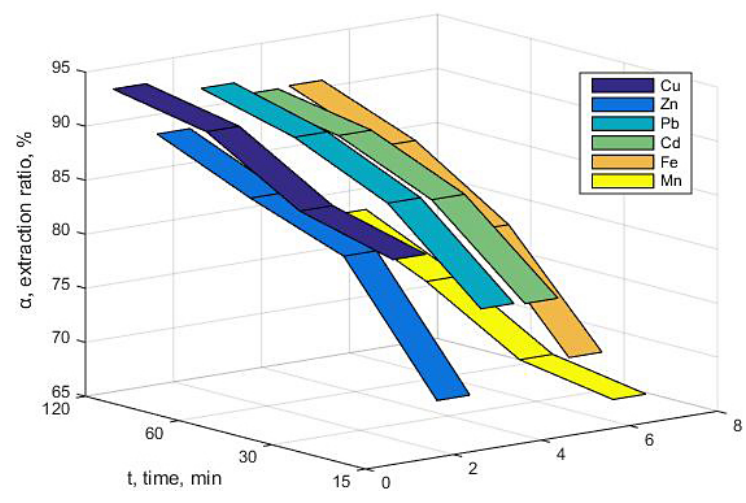

Figure 5. Metal ions extraction by bentonite clay (fractions $1.0-2.5 \mathrm{~mm}$ )

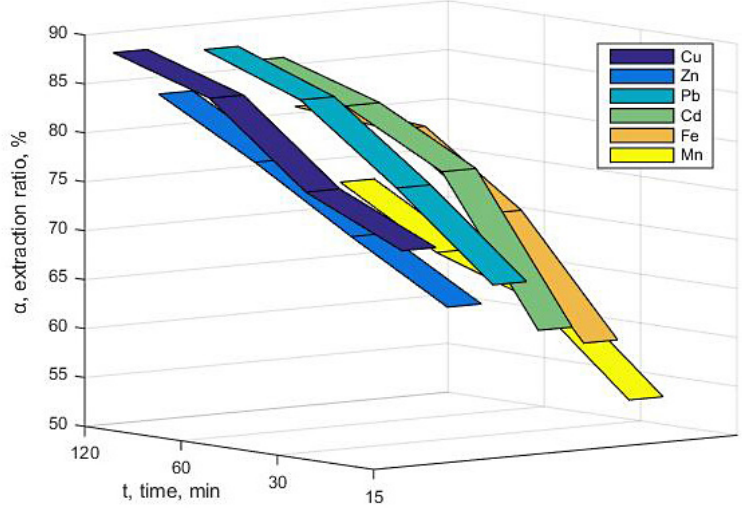

Figure 6. Metal ions extraction by bentonite clay (fractions $3.0-5.0 \mathrm{~mm}$ )

As it can be seen from the obtained data and graphs related to it, high degree of purification s provided by the sorbent with the least fraction of granules. The lesser particles size is, greater bigger the specific surface. Wastewater purification with bentonite clay shows better results than purification with shungite. However, the indices of purification with these sorbents do not achieve MPC norms for all metal ions.

It is suggested to use mechanical activation method in sorbent production technology for water purification in order to improve its sorption

Table 3. The results of the studies on sorption with ultra-dispersed shungite

\begin{tabular}{|c|c|c|c|c|c|c|c|c|c|c|}
\hline \multirow{3}{*}{ Metal ions } & \multirow{3}{*}{$\begin{array}{l}\mathrm{C}_{\text {initial' }} \\
\mathrm{mg} / \mathrm{dm}^{3}\end{array}$} & \multirow{3}{*}{$\begin{array}{l}\mathrm{MPC} \\
\mathrm{mg} / \mathrm{dm}^{3}\end{array}$} & \multicolumn{8}{|c|}{ Sorption time, minutes } \\
\hline & & & \multicolumn{2}{|c|}{15} & \multicolumn{2}{|c|}{30} & \multicolumn{2}{|c|}{60} & \multicolumn{2}{|c|}{120} \\
\hline & & & $\begin{array}{c}\text { Cresidual, } \\
\mathrm{mg} / \mathrm{dm}^{3}\end{array}$ & $\alpha, \%$ & $\begin{array}{c}\text { Cresidual, } \\
\mathrm{mg} / \mathrm{dm}^{3}\end{array}$ & $\alpha, \%$ & $\begin{array}{c}\text { Cresidual, } \\
\mathrm{mg} / \mathrm{dm}^{3}\end{array}$ & $\alpha, \%$ & $\begin{array}{c}\text { Cresidual, } \\
\mathrm{mg} / \mathrm{dm}^{3}\end{array}$ & $\alpha, \%$ \\
\hline Copper & 5.6 & 0.001 & 0.09 & 98.42 & 0.002 & 99.96 & 0.0009 & 99.98 & 0.0005 & 99.99 \\
\hline Zinc & 84.3 & 0.01 & 0.074 & 99.91 & 0.035 & 99.35 & 0.017 & 99.98 & 0.009 & 99.99 \\
\hline Lead & 5.5 & 0.006 & 0.011 & 99.77 & 0.007 & 99.85 & 0.0065 & 99.86 & 0.0058 & 99.89 \\
\hline Cadmium & 1.6 & 0.005 & 0.015 & 98.92 & 0.008 & 99.42 & 0.004 & 99.71 & 0.0023 & 99.83 \\
\hline Iron & 5.0 & 0.1 & 0.105 & 98.09 & 0.102 & 98.14 & 0.05 & 99.09 & 0.025 & 99.54 \\
\hline Manganese & 6.0 & 0.01 & 0.025 & 99.61 & 0.013 & 99.8 & 0.009 & 99.86 & 0.006 & 99.89 \\
\hline
\end{tabular}

Table 4. The results of the studies on sorption with ultra-dispersed bentonite clay

\begin{tabular}{|l|c|c|c|c|c|c|c|c|c|}
\hline \multirow{2}{*}{ Metal ions } & \multirow{2}{*}{$\begin{array}{c}\mathrm{C}_{\text {initial' }} \\
\mathrm{mg} / \mathrm{dm}^{3}\end{array}$} & \multicolumn{2}{|c|}{15} & \multicolumn{2}{|c|}{30} & \multicolumn{2}{c|}{60} & \multicolumn{3}{c|}{120} \\
\cline { 3 - 12 } & & $\begin{array}{c}\text { Cresidual, } \\
\mathrm{mg} / \mathrm{dm}^{3}\end{array}$ & $\alpha, \%$ & $\begin{array}{c}\text { Cresidual, } \\
\mathrm{mg} / \mathrm{dm}^{3}\end{array}$ & $\alpha, \%$ & $\begin{array}{c}\text { Cresidual, } \\
\mathrm{mg} / \mathrm{dm}^{3}\end{array}$ & $\alpha, \%$ & $\begin{array}{c}\text { Cresidual, } \\
\mathrm{mg}^{\prime} / \mathrm{dm}^{3}\end{array}$ & $\alpha, \%$ \\
\hline Copper & 5.6 & 0.07 & 98.75 & 0.001 & 99.98 & 0.0008 & 99.99 & 0.0007 & 99.99 \\
\hline Zinc & 84.3 & 0.04 & 99.95 & 0.0009 & 99.99 & 0.0006 & 99.99 & 0.0004 & 99.99 \\
\hline Lead & 5.5 & 0.009 & 99.84 & 0.005 & 99.90 & 0.0045 & 99.92 & 0.0031 & 99.94 \\
\hline Cadmium & 1.6 & 0.008 & 99.50 & 0.005 & 99.69 & 0.003 & 99.81 & 0.0022 & 99.86 \\
\hline Iron & 5.0 & 0.103 & 97.94 & 0.009 & 99.82 & 0.007 & 99.86 & 0.006 & 99.88 \\
\hline Manganese & 5.6 & 0.015 & 99.73 & 0.008 & 99.85 & 0.005 & 99.91 & 0.003 & 99.95 \\
\hline
\end{tabular}


capacity. When the ground sorbent undergoes mechanical activation, it has excess energy that is accumulated during the grinding process. This determines the kinetics of different heterogeneous processes going on the surface of the sorbent where finely dispersed solid particles are involved. It should be emphasized that mechanical activation renders new sorption qualities to the ground materials. This is why ground sorbents underwent mechanical activation until the ultra-dispersed state. The results of the conducted studies on ultradispersed shungite and bentonite clay at different sorption time are provided in Tables 3 and 4.

According to the obtained data (Table 4), sorption with ultra-dispersed bentonite clay under

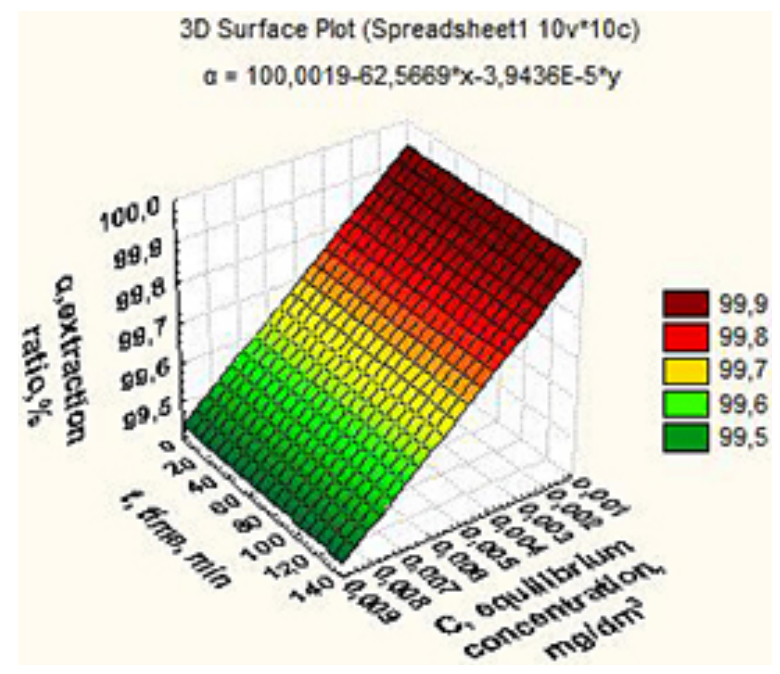

Figure 7. The graph of cadmium ions extraction degree dependency on the time of contact with ultra-dispersed bentonite clay

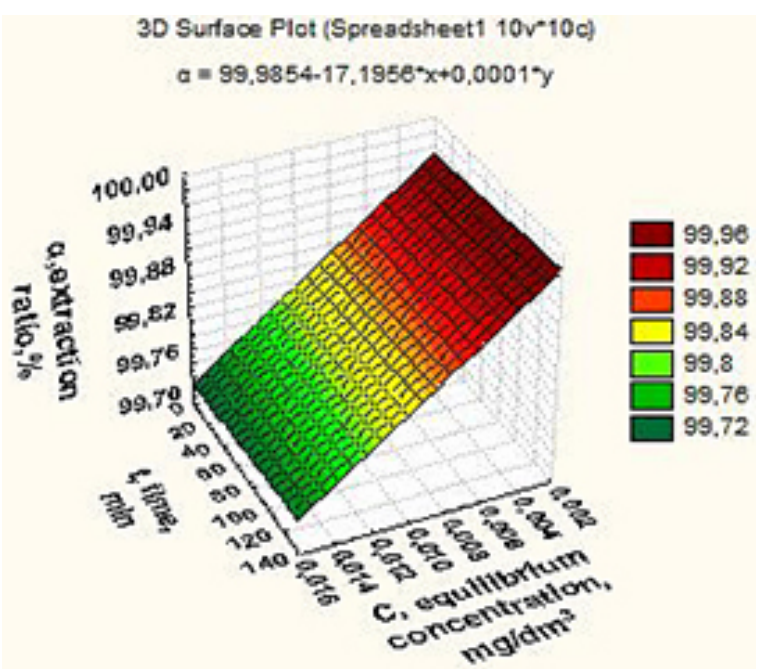

Figure 8. The graph of manganese ions extraction degree dependency on the time of contact with ultra-dispersed bentonite clay static conditions goes on with high speed after 30 minutes purification in relation to the ions of copper, zinc, lead, cadmium, iron, manganese and achieves norms. After 60 minutes of sorption with ultra-dispersed shungite, indices achieve the MPC norms for all the elements (Table 3). Experiments enabled to find that bentonite clay is a prospective, cost-effective material for wastewater purification up to the MPC norms within a short period of time. It should be noted that an MPC exceedance (cadmium and manganese content) was observed in the water of the Krasnoyarka river within the Irtyshsky mine operation area. The following graphs were built for perception convenience according to the obtained experimental data. They are graphs of the main impact factors dependencies on optimization parameters for sorption with ultra-dispersed bentonite clay related to the metals represented in Figures 7 and 8.

It was found that under any conditions of carrying out the experiment, there is the common tendency of extraction degree increase as the sorption time is prolonged. Thus, the conducted experimental studies proved that bentonite clay is one of the most prospective materials for the purification of mine wastewater. Besides, the required condition is to solve the problem of sorbents quality improvement that will enable to enhance the properties of natural materials, reduce the consumption of expensive materials, and improve the quality of discharged industrial wastewater, thus contributing to environment protection from adverse impact.

\section{CONCLUSIONS}

The studies on sorption purification of mine wastewater with natural non-activated shungite and bentonite clay in dependence on their fraction composition were carried out. The research results proved that grinding sorbents from 0.5 to $5.0 \mathrm{~mm}$ does not provide normative MPC indices for all studied metal ions.

Purification of wastewater with ultra-dispersed bentonite clay resulted in higher efficiency indicators for all the elements than the purification with ultra-dispersed shungite. The content of metal ions in fishery water bodies is within the MPC norms after 30 minutes purification with ultra-dispersed bentonite clay. It was established that the use of ultra-dispersed bentonite clay causes extraction of cadmium and manganese ions for 30 minutes up to $99.69 \%$ and 
$99.85 \%$, respectively. The conducted studies on the efficiency of produced ultra-dispersed sorbent proved that intensive mechanical activation of sorbents results in considerable qualitative changes of their composition.

The obtained results enable to justify high efficiency of the suggested ultra-dispersed sorbent (bentonite clay) and opportunities to achieve the indices that comply with the sanitary regulations for discharging treated wastewater into surface water bodies.

\section{REFERENCES}

1. Agilent. 2019. ICP-MS Agilent $7500 \mathrm{cx}$ inductively coupled plasma mass spectrometer manufactured by Agilent Technologies. http://www.myco-analytical. com/product/agilent-7500cx-icpms. Accessed 13 March 2019.

2. Al-Qodah, Z., Al-Shannag, M. 2017. Heavy metal ions removal from wastewater using electrocoagulation processes: A comprehensive review. Separation Science and Technology, 1-28.

3. Ali A., Quist-Jensen C. A., Jørgensen M. K., Siekierka A., Christensen M. L., Bryjak M., Drioli E. 2021. A review of membrane crystallization, forward osmosis and membrane capacitive deionization for liquid mining. Resources, Conservation and Recycling, 168, 105273.

4. Aziz B.K., Shwan D. M. S., Kaufhold S. 2019. Characterization of Tagaran natural clay and its efficiency for removal of cadmium (II) from Sulaymaniyah industrial zone sewage. Environmental Science and Pollution Research, 27, 38384-38396

5. Brahmi K., Bouguerra W., Harbi S., Elaloui E., Loungou M., Hamrouni B. 2018. Treatment of heavy metal polluted industrial wastewater by a new water treatment process: ballasted electroflocculation. Journal of Hazardous Materials, 344, 968-980.

6. Daumova G.K., Abdulina S.A., Kokayeva G.A., Adilkanova M.A. 2018. Experimental studies on wastewater sorption treatment with subsequent disposal of used sorbents. Chemical Engineering Transactions, 70, 2125-2130.

7. Djab M, Makhoukhi B. 2018. Adsorption of Cadmium onto modified bentonites from aqueous solutions. Journal of Materials and Environmental Sciences, 9, 2238-2246.

8. Droste R.L., Gehr R.L. 2019. Theory and practice of water and wastewater treatment. Wiley, Hoboken, NJ, USA, ISBN: 978-1-119-31237-6.

9. Ermolenko A. 2020. Sorbent Based on Polyvinyl Butyral and Potassium Polytitanate for Purifying Wastewater from Heavy Metal Ions. Processes, 8, 690.
10. Iakovleva E., Sillanpää M. 2020. Novel sorbents from low-cost materials for water treatment. Advanced Water Treatment. 265-359.

11. Koliehova A., Trokhymenko H., Melnychuk, S., Gomelya, M. 2019. Treatment of Wastewater Containing a Mixture of Heavy Metal Ions (Copper-Zinc, Copper-Nickel) using Ion-Exchange Methods. Journal of Ecological Engineering, 20(11), 146-151.

12. Kumrić K.R., Đukić A.B., Trtić-Petrović T.M., Vukelić N.S., Stojanović Z., Grbović Novaković J.D., Matović L.L. 2013. Simultaneous Removal of Divalent Heavy Metals from Aqueous Solutions Using Raw and Mechanochemically Treated Interstratified Montmorillonite/Kaolinite Clay. Industrial \& Engineering Chemistry Research, 52:7930-7939.

13. Mamyachenkov S.V., Adryshev A.K., Seraya N.V., Khairullina A.A., Daumova G.K. 2017 Nanostructured Complex Sorbent for Cleaning Heavy Metal Ions from Industrial Effluent. Metallurgist, 61, 615-623.

14. Masindi V., Gitari M.W., Tutu H, DeBeer M. 2017. Synthesis of cryptocrystalline magnesite-bentonite clay composite and its application for neutralization and attenuation of inorganic contaminants in acidic and metalliferous mine drainage. Journal of Water Process Engineering, 15, 2-17.

15. Masindi V, Muedi K.L. 2018. Environmental Contamination by Heavy Metals. Heavy Metals. 1151-1235.

16. Pandey S. 2017. A comprehensive review on recent developments in bentonite-based materials used as adsorbents for wastewater treatment. Journal of Molecular Liquids, 241, 1091-1113.

17. Pawar R.R, Lalhmunsiama Bajaj H.C, Lee S.M. 2016. Activated bentonite as a low-cost adsorbent for the removal of $\mathrm{Cu}$ (II) and $\mathrm{Pb}$ (II) from aqueous solutions: Batch and column studies. Journal of Industrial and Engineering Chemistry, 34, 213-223.

18. Płaza A., Kołody 'nska D., Hałas P., Geca M., Franus M., Hubicki Z. 2017. The zeolite modified by chitosan as an adsorbent for environmental applications. Adsorp. Sci. Technol, 35, 834-844.

19. Rajasulochana P., Preethy V. 2016. Comparison on efficiency of various techniques in treatment of waste and sewage water - A comprehensive review. Resource-Efficient Technologies, 2(4), 175-184.

20. Rambabu, K., Banat, F., Pham, Q. M., Ho, S.-H., Ren, N.-Q., \& Show, P. L. 2020. Biological remediation of acid mine drainage: Review of past trends and current outlook. Environmental Science and Ecotechnology, 2, 100024.

21. Shahmirzadi M.A.A., Hosseini S.S., Luo J., Ortiz I. 2018. Significance, evolution and recent advances in adsorption technology, materials and processes for desalination, water softening and salt removal. J. Environ. Manag, 215, 324-344 
22. Tezcan Un. U., Onpeker S.E., Ozel E. 2017. The treatment of chromium containing wastewater using electrocoagulation and the production of ceramic pigments from the resulting sludge. Journal of Environmental Management, 200, 196-203.

23. Toor M., Jin B., Dai S., Vimonses V. 2015. Activating natural bentonite as a cost-effective adsorbent for removal of Congo-red in wastewater. Journal of Industrial and Engineering Chemistry, 21, 653-661.

24. Uddin M.K. 2017. A review on the adsorption of heavy metals by clay minerals, with special focus on the past decade. Chemical Engineering Journal, 308, 438-462.

25. Xue C., Qi P., Liu Y. 2018. Adsorption of aquatic $\mathrm{Cd}^{2+}$ using a combination of bacteria and modified carbon fiber. Adsorp. Sci. Technol, 36, 857-871.
26. Yenial Ü., Bulut G. 2017. Examination of flotation behavior of metal ions for process water remediation. Journal of Molecular Liquids, 241, 130-135.

27. Zheng X., Zhang Z., Yu D., Chen X., Cheng R., Min S., Wang J., Xiao Q., Wang J. 2015. Overview of membrane technology applications for industrial wastewater treatment in China to increase water supply. Resources, Conservation and Recycling, 105, 1-10.

28. Zhu Y., Dou P., He H., Lan H., Xu S., Zhang Y., Niu J. 2020. Improvement of permeability and rejection of an acid resistant polysulfonamide thin-film composite nanofiltration membrane by a sulfonated poly(ether ether ketone) interlayer. Separation and Purification Technology, 116528.

29. Zivica V., Palou M.T. 2015. Physico-chemical characterization of thermally treated bentonite. Composites Part B: Engineering, 68, 436-445 